\title{
A novel single-nucleotide polymorphism in the 5 ' upstream region of the prolactin receptor gene is associated with fiber traits in Liaoning cashmere goats
}

\author{
J.P. Zhou' ${ }^{1}$, X.P. Zhu' ${ }^{1}$, W. Zhang ${ }^{1}$, F. Qin ${ }^{1}$, S.W. Zhang ${ }^{2}$ and Z.H. Jia' \\ ${ }^{1}$ State Key Laboratory for Animal Nutrition, \\ College of Animal Science and Technology, \\ China Agricultural University, Beijing, P.R. China \\ ${ }^{2}$ Liaoning Cashmere Goat Breeding Center, Liaoning, P.R. China
}

Corresponding author: Z.H. Jia

E-mail: jzh331@cau.edu.cn

Genet. Mol. Res. 10 (4): 2511-2516 (2011)

Received February 1, 2011

Accepted August 30, 2011

Published October 13, 2011

DOI http://dx.doi.org/10.4238/2011.October.13.8

\begin{abstract}
The most important traits of Chinese Liaoning cashmere goat fiber are fiber diameter, weight, and length. We looked for polymorphisms and their possible association with cashmere fiber traits in the $5^{\prime}$ upstream region (5' UTR) of the prolactin receptor gene (PRLR), which encodes an anterior pituitary peptide hormone involved in different physiological activities; it is the principal endocrine regulator in pelage replacement in mammals. A novel
\end{abstract}


single-nucleotide polymorphism (SNP) was found in the 5' UTR of PRLR by PCR-RFLP in an analysis of 590 goats. Two genotypes (CC and $\mathrm{CT}$ ) were observed. The frequencies of allele $\mathrm{C}$ and $\mathrm{T}$ were 0.93 and 0.07 , respectively. Association analysis revealed that the PRLR 5' UTR polymorphism (SNP5) was significantly associated with cashmere fiber weight and diameter. This novel SNP in hircine $P R L R$ has potential as a molecular marker for cashmere fiber weight and diameter in Liaoning cashmere goats.

Key words: Cashmere goats; Prolactin receptor; Polymorphisms; Cashmere fiber traits

\section{INTRODUCTION}

Liaoning cashmere goats (Capra hircus) are an important commodity for China, famous for their cashmere. Although the quality of the cashmere is highly acclaimed, the cashmere output is low. Increasing cashmere fiber weight (CFW) and maintaining longer cashmere fiber length (CFL) and smaller cashmere fiber diameter (CFD) are typically associated with higher economic gains for cashmere producers. China is the world's largest producer of cashmere, and thus, it is of great interest to maximize the quantity of the cashmere fiber without affecting the fiber quality.

Prolactin (PRL) has been implicated as the principal endocrine regulator in pelage replacement in a diverse array of mammals (Dicks et al., 1994; Pearson et al., 1996; Thompson Jr. et al., 1997), and all biological functions associated with PRL are mediated by its specific receptor prolactin receptor (PRLR), which is a single-pass membrane-bound protein that belongs to the cytokine receptor family (Kelly et al., 2001; Foitzik et al., 2003). Furthermore, PRLR has been shown to be expressed in the wool follicles of sheep (Choy et al., 1997), and result in hair cycle perturbations and slightly longer and coarser hair in mice (Craven et al., 2001). Therefore, in the present study a novel single-nucleotide polymorphism (SNP) in the Liaoning cashmere goat PRLR 5' untranslated region (5' UTR) associated with cashmere fiber traits is described.

\section{MATERIAL AND METHODS}

Blood samples were obtained from 590 female Liaoning cashmere goats (C. hircus). Genomic DNA was isolated from the blood samples using the BioTeke Genomic DNA kit (BioTeke) for SNP discovery and association analyses.

Cashmere trait data were gathered from the records of the Liaoning Cashmere Goat Breeding Center between 2002 and 2009. Moulted cashmere was weighed using an electronic scale. CFL was measured prior to combing without stretching the fiber, and CFD was measured using an Auda 2000 optical wool fiber gauging instrument (Shenaoda Technology Company).

To determine the PRLR 5' UTR polymorphisms, genomic DNA was amplified using polymerase chain reaction (PCR), followed directly by sequencing. PCR was carried out in a $\mathrm{C} 1000^{\mathrm{TM}}$ Thermal Cycler (Bio-Rad) with denaturation for $30 \mathrm{~s}$ at $94^{\circ} \mathrm{C}$, annealing for 
$30 \mathrm{~s}$ at $59^{\circ} \mathrm{C}$, and extension for $1 \mathrm{~min}$ at $72^{\circ} \mathrm{C}$. Each $25-\mu \mathrm{L}$ reaction mixture contained $2 \mu \mathrm{L}$ pooled DNA template, $1 \mu \mathrm{L} 2.5 \mathrm{mM}$ dNTP, $1.5 \mu \mathrm{L} 25 \mathrm{mM} \mathrm{MgCl}_{2}, 0.3 \mu \mathrm{L} 5 \mathrm{U} / \mu \mathrm{L}$ Taq DNA polymerase $(\mathrm{TaKaRa})$ and $1 \mu \mathrm{L} 10 \mu \mathrm{M}$ primers. The DNA pool was constructed from 20 genetically unrelated goats. PCR primers were designed based on the GenBank sequence EU678913.2 for $C$. hircus PRLR by the Premier 5.0 software. The primer sequence (5'-3') was as follows: P1-F: GCCAGGTTCCCAGTTCAG, P1-R: ACTGTAATCCACTAGGCTCCTC. PCR products were sequenced using the ABI3730XL DNA Analyzer (Applied Biosystems). The polymorphisms were analyzed using the Sequencher 4.2 software (Demo version, Gene Codes Corporation).

Genotypes were detected using PCR-restriction fragment length polymorphism (PCR-RFLP). To identify the PRLR 5' UTR polymorphism (SNP5), the 5' UTR PCR product was used as a template for amplification with the forward primer 5'-AGGGCTTCCATA GAGTCTCAG-3' and reverse primer 5'-ACTGTAATCCACTAGGCTCCTC-3'. A Hin1II recognition site was introduced in this fragment. PCR conditions were identical to those for polymorphism discovery. The PCR products were digested with the restriction enzyme Hin $1 \mathrm{II}$ (Fermentas Company) at $37^{\circ} \mathrm{C}$ for $6 \mathrm{~h}$. DNA fragments were separated by electrophoresis on a $4 \%$ agarose gel stained. When the Hin 1 II restriction site was present, the 162-bp fragment was digested into two fragments (136 and $26 \mathrm{bp}$ ). The TT allele was not cleaved by Hin 1 II, resulting in a single 162-bp band. Heterozygote TC allele had all three of these bands.

The linear model was applied to analyze the associations of polymorphisms with fiber traits using the SAS software package (version 9.1.3). The mixed linear model was as follows:

$$
\mathrm{Y}=\mu+\mathrm{Ye}+\mathrm{A}+\mathrm{S}+\mathrm{G}+e
$$

where $Y$ is the value of each trait (CFW, CFD, CFL), $\mu$ is the population mean, $Y e$ is the fixed effect of year, $A$ is the fixed effect of age, $S$ is the random effect of sire, $G$ is the fixed effect corresponding to the genotype, and $e$ is the random residual term.

\section{RESULTS}

According to the polymorphism validation, a novel SNP was identified in Liaoning cashmere goats at EU-678913.2 - 970 bp: C/T (C970T). At this site, only two genotypes, the $\mathrm{CC}$ homozygote and CT heterozygote, were observed, and the TT genotype was not detected in the population (Figure 1). We found 509 goats with the CC genotype, and 81 with the CT genotype. The estimated allele frequencies were $93.14 \%$ for $\mathrm{C}$ and $6.86 \%$ for $\mathrm{T}$ (Table 1 ). The results of associations between goat fiber traits and C970T of PRLR are shown in Table 2. Based on the analysis, CFW had a significant association with the C970T genotype. Goats with the CC genotype showed higher CFW than those with the CT genotype $(\mathrm{P}=0.0079)$. The difference was about $33 \mathrm{~g}$ between the $\mathrm{CC}$ genotype and $\mathrm{CT}$ genotype. These genotypes had no association with CFL and CFD. 
A
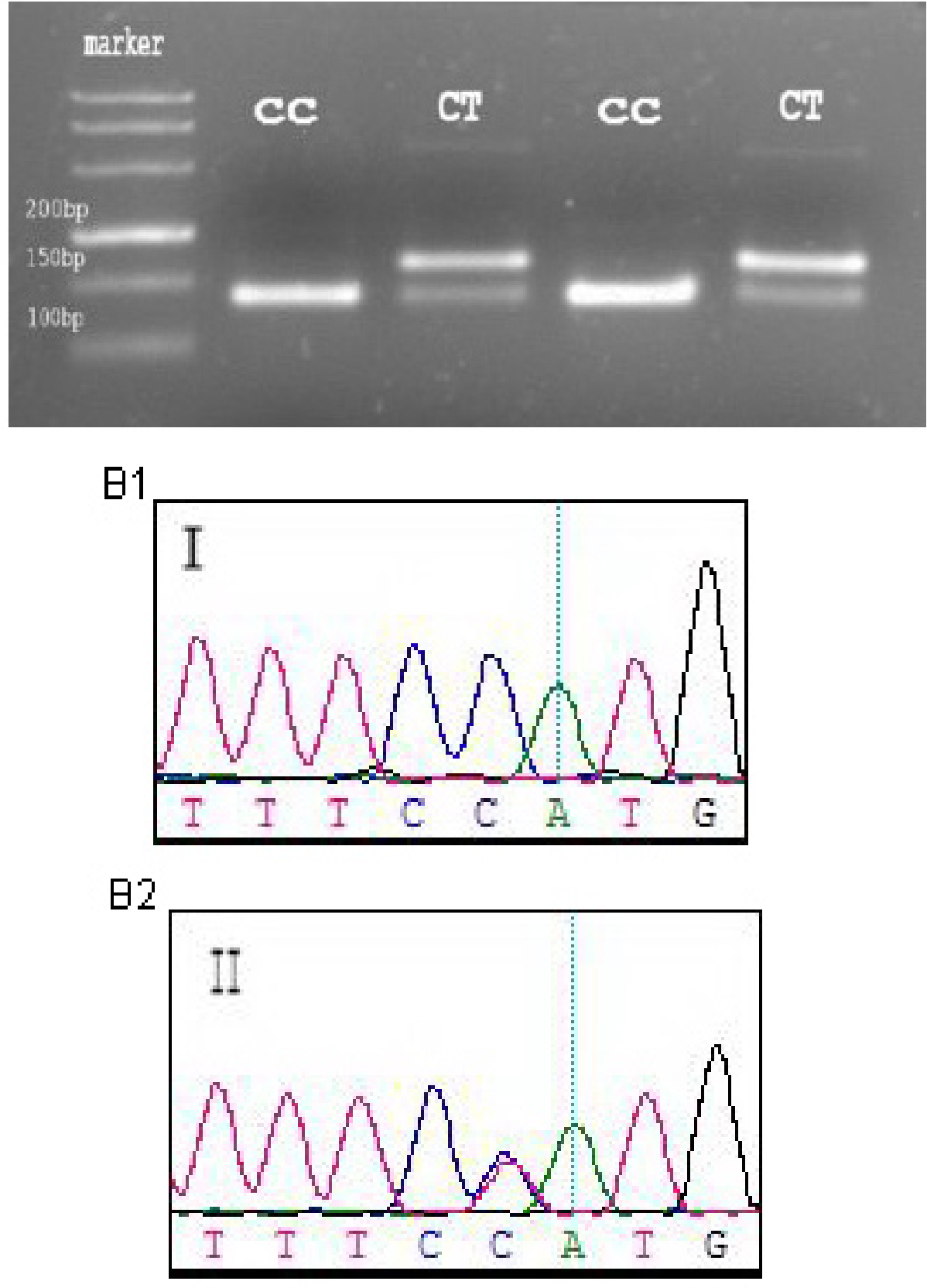

Figure 1. Genotypes of PCR-RFLP in the Capra hircus PRLR gene. A. PCR-RFLP polymorphism of 162-bp PCR products. Two RFLP patterns are visible, corresponding to the CC and CT genotypes. B. Direct sequencing of PCR products indicates the mutation $(\mathrm{C} / \mathrm{T})$ at position 970 . Sequence I (B1) occurs in the CC genotype and sequence II (B2) in the CT genotype. The double peak in sequence II shows both nucleotides $\mathrm{C}$ and $\mathrm{T}$ in the heterozygote. 
Table 1. Genotype frequencies of the PRLR single nucleotide polymorphism (SNP) in Liaoning cashmere goats.

\begin{tabular}{lccccc}
\hline SNP & Genotype & Count & Frequency $(\%)$ & Allele & Frequency (\%) \\
\hline C970T & CC & 509 & 86.27 & C & 93.14 \\
& CT & 81 & 13.73 & T & 6.86 \\
\hline
\end{tabular}

Table 2. Associations of the PRLR single nucleotide polymorphism (SNP) with goat fiber traits.

\begin{tabular}{lcccc}
\hline SNP & Genotype & Cashmere fiber weight $(\mathrm{g})$ & Cashmere fiber length $(\mathrm{cm})$ & Cashmere fiber diameter $(\mu \mathrm{m})$ \\
\hline C970T & CC & $770.15 \pm 8.61^{\mathrm{a}}$ & $7.63 \pm 0.09$ & $15.44 \pm 0.11$ \\
& CT & $737.74 \pm 13.48^{\mathrm{b}}$ & $7.64 \pm 0.14$ & $15.48 \pm 0.16$ \\
$\mathrm{P}$ & & $0.0079^{* *}$ & 0.9616 & 0.7282 \\
\hline
\end{tabular}

Data are reported as means \pm SEM. $* * \mathrm{P}<0.01$ is considered to be highly significant. ${ }^{\text {a,b }}$ Means within a column with no common superscript letters differ significantly for each SNP $(\mathrm{P}<0.05)$.

\section{DISCUSSION}

In this study, we showed that the C970T polymorphism of PRLR was associated with CFW in Liaoning cashmere goats. By scanning the 5' UTR of $P R L R$, we identified one novel SNP. However, there were only two genotypes, and the TT genotype was not detected in the study population. The TT genotype may produce a recessive lethal gene or may be linked to a recessive lethal mutation. On the other hand, this genotype may eventually be induced by the long-term artificial selection towards fiber quality. Previous studies suggest that $P R L R$ appeared to be a promising candidate gene, because it may regulate important functions in hair growth cycles (Choy et al., 1997; Nixon et al., 2002). The main finding of this study was the association of the C970T polymorphism with CFW, which has not been reported before. Changes in CFW possibly arise from changes in PRLR signal transduction. This mutation may induce a change in PRLR expression and affect downstream signaling in the JAK2/Stat5 signal transduction pathway, thus affecting PRL-induced gene transcription (Craven et al., 2006). Our results may indicate that $P R L R$ affects cashmere fiber traits directly or may regulate a major gene that controls fiber production. This C970T polymorphism may be useful for marker-assisted selection in cashmere goats. Further studies in larger populations and other cashmere goats are needed to confirm these results.

\section{CONCLUSIONS}

In conclusion, one novel polymorphism in the 5' flanking region of the $P R L R$ was identified in Liaoning cashmere goats. The present study showed that the C970T polymorphism was associated with CFW in Liaoning cashmere goats. These results indicate that the C970T polymorphism in hircine PRLR is a potential molecular marker for CFW in cashmere goats. 


\section{ACKNOWLEDGMENTS}

Research supported by the National Key Technologies R \& D Program (\#2008AA101011-01-01), P.R. China. We thank the Liaoning Cashmere Breeding Center for providing cashmere goats and production trait data. We also thank the State Key Laboratory of Agrobiotechnology staff for their help.

\section{REFERENCES}

Choy VJ, Nixon AJ and Pearson AJ (1997). Distribution of prolactin receptor immunoreactivity in ovine skin and changes during the wool follicle growth cycle. J. Endocrinol. 155: 265-275.

Craven AJ, Ormandy CJ, Robertson FG, Wilkins RJ, et al. (2001). Prolactin signaling influences the timing mechanism of the hair follicle: analysis of hair growth cycles in prolactin receptor knockout mice. Endocrinology 142: 2533-2539.

Craven AJ, Nixon AJ, Ashby MG, Ormandy CJ, et al. (2006). Prolactin delays hair regrowth in mice. J. Endocrinol. 191: 415-425.

Dicks P, Russel AJ and Lincoln GA (1994). The role of prolactin in the reactivation of hair follicles in relation to moulting in cashmere goats. J. Endocrinol. 143: 441-448.

Foitzik K, Krause K, Nixon AJ, Ford CA, et al. (2003). Prolactin and its receptor are expressed in murine hair follicle epithelium, show hair cycle-dependent expression, and induce catagen. Am. J. Pathol. 162: 1611-1621.

Kelly PA, Binart N, Freemark M, Lucas B, et al. (2001). Prolactin receptor signal transduction pathways and actions determined in prolactin receptor knockout mice. Biochem. Soc. Trans. 29: 48-52.

Nixon AJ, Ford CA, Wildermoth JE, Craven AJ, et al. (2002). Regulation of prolactin receptor expression in ovine skin in relation to circulating prolactin and wool follicle growth status. J. Endocrinol. 172: 605-614.

Pearson AJ, Parry AL, Ashby MG, Choy VJ, et al. (1996). Inhibitory effect of increased photoperiod on wool follicle growth. J. Endocrinol. 148: 157-166.

Thompson DL Jr, Hoffman R and DePew CL (1997). Prolactin administration to seasonally anestrous mares: reproductive, metabolic, and hair-shedding responses. J. Anim. Sci. 75: 1092-1099. 